\title{
Lund exhaust on hemodynamic parameters and inflammatory mediators in patients undergoing cardiac valve replacement under cardiopulmonary bypass
}

\author{
JIHONG ZHU ${ }^{1}$, WEIMIN ZHANG ${ }^{2}$, GUOYING SHEN $^{3}$, XIN YU $^{1}$, JIGE GUO $^{2}$ and TAIDI ZHONG ${ }^{1}$ \\ ${ }^{1}$ Department of Anesthesiology, ${ }^{2}$ Heart Center, ${ }^{3}$ Out-patient Department, \\ Sir Run Run Shaw Hospital of Zhejiang University, Hangzhou, Zhejiang 310016, P.R. China
}

Received January 8, 2018; Accepted June 21, 2018

DOI: $10.3892 /$ etm.2018.6354

\begin{abstract}
The effect of Lund exhaust technique on hemodynamics and inflammatory mediators in patients undergoing cardiac valve replacement under cardiopulmonary bypass was evaluated. A total of 60 patients with heart disease undergoing elective heart valve replacement under elective cardiopulmonary bypass were randomly divided into Lund exhaust group (group A) and control group (group B), with 30 patients in each group. Group A underwent Lund exhaust during cardiopulmonary bypass, while group B was identical to group A except for not using the Lund exhaust technique during cardiopulmonary bypass. The hemodynamic parameters at different time-points showed that the indexes of MAP, PASP, CO, CI, PCWP, CVP and SVR in $\mathrm{T}_{1}, \mathrm{~T}_{2}, \mathrm{~T}_{3}$ and $\mathrm{T}_{4}$ moments between group A and group $\mathrm{B}$ were statistically significant $(p<0.05)$. There was no statistical significance in IL-6, IL-8, IL-10, TNF- $\alpha$ and TIMP-1 between group A and group B patients at the $\mathrm{T}_{0}$ moment $(\mathrm{p}>0.05)$. The levels of IL-6, IL-8, IL-10, TNF- $\alpha$ and TIMP-1 in group B patients at $T_{1}, T_{2}, T_{3}$ and $\mathrm{T}_{4}$ moments were statistically significant compared with those in group A $(\mathrm{p}<0.05)$. The IL-6, IL-8, TNF- $\alpha$ indexes of group $B$ patients were statistically significant at the $\mathrm{T}_{5}$ moment compared with those in group A $(\mathrm{p}<0.05)$. The IL-10 and TIMP-1 of two groups were not statistically significant at the $\mathrm{T}_{5}$ moment. The operating time, $\mathrm{CPB}$ time, aortic clamp time, intraoperative blood loss, postoperative tube time, ICU stay time, hospital stay time and pulmonary infection of patients in group A were significantly less than those in group B. In conclusion, Lund exhaust technology can significantly reduce the fluctuation of hemodynamics, decrease the expression of
\end{abstract}

Correspondence to: Dr Jihong Zhu, Department of Anesthesiology, Sir Run Run Shaw Hospital of Zhejiang University, 3 Qingchun East Road, Hangzhou, Zhejiang 310016, P.R. China

E-mail: aovlk233@163.com

Key words: Lund exhaust technology, heart valve replacement, hydrodynamics index, inflammatory factors inflammatory factors, improve lung function, and is conducive to the rehabilitation of patients.

\section{Introduction}

Valvular heart disease refers to the mitral valve, three tricuspid valve, aortic valve and pulmonary valve for rheumatic fever, mucoid degeneration, degenerative changes, congenital malformation, trauma, infection or appearance of necrosis lesions, affecting the flow of blood resulting in abnormal cardiac function and eventually leading to heart failure. The most frequently involved valve is the mitral valve, followed by the aortic valve. The disease often occurs at the age of 20-40 years, and 2/3 are female, and with more rheumatic fever history $(1,2)$. Heart valve disease is an increasingly common and serious disease. There is no effective biological diagnosis or treatment strategy. The only option is to perform prosthetic valve replacement (3).

It is a common technique in modern surgery undergoing cardiac valve replacement with cardiopulmonary bypass (CPB). Although there is rich experience in the conventional cardiac valve surgery, the postoperative complications and the mortality rate is much higher than other treatments (e.g. mortality rate up to $2-5 \%$ ) (4). CPB machine makes the heart vein blood flow through the outside systemic circulation and provide the oxygenated blood back to the artery system with temperature regulation and filtration $(5,6)$. Moreover, CPB pipeline helps blood components avoid the non-physiological interface contaction, bubble residue, ischemia-reperfusion, temperature changes and other factors that trigger the activation and injury of vascular endothelial cells and other consequences $(7,8)$.

There are many studies on the complications of cardiac valve replacement under CPB worldwide. For example, the study of Yang et al (9) found that sevoflurane is better than propofolum in perioperative myocardial protection, inhibiting inflammatory reaction and shortens the hospitalization time of propofol and ICU. Under extracorporeal circulation use of tranexamic acid in cardiac surgery can effectively reduce intraoperative and postoperative bleeding. Liu et al (4) showed that under extracorporeal circulation with heart valve replacement surgery tranexamic acid can effectively reduce 
postoperative bleeding. CPB is prone to brain damage in heart valve replacement surgery. The mechanism may be the inflammatory reaction caused by anesthesia, operation trauma and stress reaction, which results in the increase of bloodbrain barrier permeability, secondary brain edema and brain damage. At the same time, the formation of cerebral thrombosis and the changes of cerebral ischemia, hypoxia and imbalance of oxygen supply and demand caused by low blood perfusion during the course of CPB patients are also important causes of brain injury $(10,11)$. Dexmedetomidine can reduce the release of neuroendocrine hormones and inflammatory mediators, maintain intracranial metabolism, and protect the brain in patients with ischemic brain injury (12). Residual bubbles in heart surgery stranded in the heart cavity and pulmonary vein system in cardiac resuscitation after cardiac cardioversion or after cardiopulmonary can easily bypass access to the left heart system, left ventricular dysfunction, fatal arrhythmia and short or long-term abnormal nerve function after surgery.

There are relatively few studies on this subject. In this study, we examined patients who underwent open heart valve surgery using the Lund exhaust technology and those that did not undergo Lund exhaust technology (control group). We examined hemodynamic parameters, mean arterial pressure (MAP), central venous pressure (CVP), pulmonary arterial pressure (PASP), pulmonary capillary wedge pressure (PCWP), systemic circulation resistance (SVR), cardiac output (CO) and cardiac index (CI), as well as the levels of inflammatory mediators [plasma interleukin-6 (IL-6), plasma interleukin-8 (IL-8), plasma interleukin-10 (IL-10), tumor necrosis factor $\alpha$ (TNF- $\alpha$ ) and plasma tissue inhibitor of metalloproteinase (TIMP-1)] at different time-points in order to investigate the clinical efficacy and safety of this technology.

\section{Patients and methods}

Patients enrolled in the study. The study was carried out in Sir Run Run Shaw Hospital of Zhejiang University (Hangzhou, China). Informed consent was signed by all the participants or their families. Sixty patients, aged 35-65 years, were selected from May 2016 to May 2017 in our hospital undergoing cardiac valve replacement under CPB and ASA II-IV (ASA grade according to the American Society of anesthesiologists). Inclusion criteria were: the circulatory system was stable and the patient had no autoimmune diseases. There was no cardiovascular and systemic complications, and there was no obvious abnormality or impairment of liver and kidney function. CPB undergoing cardiac valve replacement was successful (stop CPB and succeed once, a successful heart resuscitatio and no abnormal bleeding). Exclusion criteria were: patients with cardiovascular related diseases and liver and kidney dysfunction, $\mathrm{CPB}$ failure and thus repeat of $\mathrm{CPB}$, reoperation and $\mathrm{CPB}$ again after operation, those with immune system and hematological diseases, the use of glucocorticoids before operation, combined with other surgical complications or adverse reactions and others. Preoperative cardiac function was assessed by NYHA classification and plasma concentrations of amino terminal natriuretic peptide (NT-proBNP). Sixty patients were randomly divided into the Lund exhaust group (group A) and control group (group B), 30 cases in each group. The difference in age, body mass,
Table I. Patient characteristics (mean \pm SD).

\begin{tabular}{lcc}
\hline Patient characteristics & Group A (n=30) & Group B $(\mathrm{n}=30)$ \\
\hline Age (year) & $53.42 \pm 6.49$ & $56.90 \pm 8.41^{\mathrm{a}}$ \\
Weight $(\mathrm{kg})$ & $59.50 \pm 6.67$ & $61.44 \pm 8.75^{\mathrm{a}}$ \\
Height $(\mathrm{cm})$ & $170.09 \pm 7.73$ & $171.75 \pm 6.63^{\mathrm{a}}$ \\
Sex $(\mathrm{M} / \mathrm{F})$ & $18 / 22$ & $19 / 21^{\mathrm{a}}$ \\
ASA class & II-IV & $\mathrm{II}^{\mathrm{I}}-\mathrm{IV}^{\mathrm{a}}$ \\
EF $(\%)$ & $55.7 \pm 5.21$ & $57.4 \pm 5.53^{\mathrm{a}}$
\end{tabular}

${ }^{\mathrm{a}}$ For group B, compared with group A, $\mathrm{p}<0.05$.

cardiac output and ASA classification between the two groups was not statistically significant ( $\mathrm{p}>0.05)$, as shown in Table I. The Ethics Committee of Sir Run Run Shaw Hospital of Zhejiang University approved the study and informed consent was signed by all the prticipants or their families.

\section{Methods}

Anesthesia. The ECG, blood pressure, pulse oxygen saturation and end tidal carbon dioxide partial pressure (ECG) were monitored in the two groups after admission. The central venous pressure (CVP) was monitored by internal jugular vein puncture under local anesthesia of lidocaine. All patients were given anesthesia induction with midazolam $0.1-0.2 \mathrm{mg} / \mathrm{kg}$, vecuronium $0.15-0.2 \mathrm{mg} / \mathrm{kg}$, sufentanil $1-2 \mu \mathrm{g} / \mathrm{kg}$, etomidate $0.15-0.3 \mathrm{mg} / \mathrm{kg}$, endotracheal intubation for mechanical ventilation. All patients were given vecuronium $0.1-0.15 \mathrm{mg} /(\mathrm{kg} \cdot \mathrm{h})$, sufentanil $0.5-1.5 \mu \mathrm{g} /(\mathrm{kg} \cdot \mathrm{h})$, propofol $6-10 \mathrm{mg} /(\mathrm{kg} \cdot \mathrm{h})$ to maintain anesthesia. The mean arterial pressure (MAP) remained at $60-80 \mathrm{mmHg}$. Hemodynamic parameters of all patients were closely monitored and recorded.

$C P B$ methods. All patients underwent median sternotomy by longitudinal incision of the pericardium to expose the heart, heparin $3 \mathrm{mg} / \mathrm{kg}$ anticoagulation to maintain the activation of whole blood coagulation time $($ ACT) $>480 \mathrm{sec}$. All patients were treated with a Jostar artificial heart lung machine (Maquet Critical Care AB, Sweden), with a pre-cast liquid crystalline adhesive over 1:1, with the addition of a strengthening dragon, $20 \%$ mannitol, and $5 \%$ sodium bicarbonate. The nasopharynx temperature was maintained at $28-30^{\circ} \mathrm{C}$ in all patients. After blocking-up the ascending aorta, myocardial perfusion was performed by perfusion of 4:1 oxygenated blood cardioplegia. After the end of CPB, protamine and heparin (1.5:1) were routinely given.

Twenty-five patients from group A were treated with Lund exhaust technique. The Lund exhaust technique is to complete the operation in the heart after aortic root open and fully attract aorta through small incision bilateral pleural lung collapsed during CPB, placed 20 continuous suction exhaust with ventricular apex artery trocar left. The heart rebeating group without left ventricular ejection, started a half tidal volume in the bubble or by the esophageal echocardiography under continuous monitoring ventilation with end expiratory positive pressure at $5 \mathrm{~cm} \mathrm{H}_{2} \mathrm{O}$, myocardial stunning was not observed after recovery of the left ventricular preload; air embolism was not found in the left 
Table II. Comparison of hemodynamics at different time-points before and after operation in two groups $(\mathrm{n}=30$, mean \pm SD).

\begin{tabular}{|c|c|c|c|c|c|c|c|}
\hline Indices & Groups & $\mathrm{T}_{0}$ & $\mathrm{~T}_{1}$ & $\mathrm{~T}_{2}$ & $\mathrm{~T}_{3}$ & $\mathrm{~T}_{4}$ & $\mathrm{~T}_{5}$ \\
\hline MAP & Group A & $81.23 \pm 9.08$ & $76.69 \pm 8.53$ & $77.92 \pm 6.06$ & $80.85 \pm 7.73$ & $80.31 \pm 6.36$ & $83.08 \pm 9.66$ \\
\hline$(\mathrm{mmHg})$ & Group B & $83.10 \pm 9.93$ & $72.90 \pm 10.04^{\mathrm{a}}$ & $83.40 \pm 7.43^{\mathrm{a}}$ & $86.60 \pm 10.59^{a}$ & $88.60 \pm 10.99^{a}$ & $83.50 \pm 9.58$ \\
\hline PASP & Group A & $24.31 \pm 6.88$ & $22.62 \pm 6.16$ & $23.54 \pm 7.83$ & $21.15 \pm 3.16$ & $20.01 \pm 3.69$ & $21.77 \pm 4.19$ \\
\hline$(\mathrm{mmHg})$ & Group B & $21.10 \pm 5.86$ & $17.60 \pm 5.36^{\mathrm{a}}$ & $26.20 \pm 5.77^{a}$ & $26.70 \pm 5.56^{\mathrm{a}}$ & $23.50 \pm 4.65^{\mathrm{a}}$ & $20.90 \pm 4.58$ \\
\hline $\mathrm{CO}$ & Group A & $3.78 \pm 0.84$ & $4.29 \pm 0.73$ & $4.87 \pm 0.84$ & $5.21 \pm 0.76$ & $5.41 \pm 0.43$ & $5.35 \pm 0.45$ \\
\hline$(1 / \min )$ & Group B & $3.18 \pm 0.57$ & $3.18 \pm 0.65^{\mathrm{a}}$ & $3.46 \pm 0.37^{\mathrm{a}}$ & $4.11 \pm 0.54^{\mathrm{a}}$ & $4.31 \pm 0.61$ & $4.77 \pm 0.31$ \\
\hline $\mathrm{CI}$ & Group A & $2.32 \pm 0.74$ & $2.47 \pm 0.55$ & $2.52 \pm 0.53$ & $3.21 \pm 0.76$ & $3.31 \pm 0.86$ & $3.42 \pm 0.78$ \\
\hline $1 /\left(\min \cdot \mathrm{m}^{2}\right)$ & Group B & $2.04 \pm 0.55$ & $2.19 \pm 0.55^{\mathrm{a}}$ & $2.26 \pm 0.62^{\mathrm{a}}$ & $2.12 \pm 0.68^{\mathrm{a}}$ & $2.45 \pm 0.65^{\mathrm{a}}$ & $3.06 \pm 0.63$ \\
\hline PCWP & Group A & $16.50 \pm 3.03$ & $19.10 \pm 4.76$ & $16.1 \pm 4.01$ & $14.20 \pm 3.61$ & $14.80 \pm 2.89$ & $13.40 \pm 2.72$ \\
\hline$(\mathrm{mmHg})$ & Group B & $15.70 \pm 3.56$ & $13.70 \pm 3.13^{\mathrm{a}}$ & $12-.50 \pm 3.69^{a}$ & $10.91 \pm 3.71 \mathrm{a}$ & $11.20 \pm 1.62^{\mathrm{a}}$ & $13.51 \pm 1.58$ \\
\hline CVP & Group A & $9.80 \pm 2.66$ & $10.80 \pm 2.62$ & $11.40 \pm 4.14$ & $10.50 \pm 3.24$ & $10.30 \pm 2.83$ & $10.10 \pm 2.92$ \\
\hline$(\mathrm{mmHg})$ & Group B & $11.50 \pm 2.81$ & $7.90 \pm 2.513^{\mathrm{a}}$ & $7.40 \pm 3.983^{\mathrm{a}}$ & $8.21 \pm 2.463^{\mathrm{a}}$ & $8.10 \pm 2.903^{\mathrm{a}}$ & $11.40 \pm 3.633^{\mathrm{a}}$ \\
\hline SVR & Group A & $1,582.50 \pm 141.86$ & $1,472.60 \pm 198.81$ & $1,469.50 \pm 195.16$ & $1,111.67 \pm 177.68$ & $1,295.4 \pm 149.06$ & $1,418.01 \pm 142.16$ \\
\hline$(\mathrm{kPa} \cdot \mathrm{s} / \mathrm{l})$ & Group B & $1,677.10 \pm 157.65$ & $1,779.8 \pm 160.73^{\mathrm{a}}$ & $1,759.4 \pm 174.75^{\mathrm{a}}$ & $1,599.5 \pm 199.17^{\mathrm{a}}$ & $1,494.9 \pm 141.07^{\mathrm{a}}$ & $1,590.2 \pm 154.60$ \\
\hline
\end{tabular}

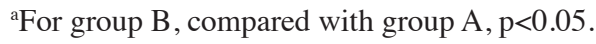

ventricular cavity after the normal tidal volume ventilation at the same time. The left ventricular ejection was resumed and the circulatory stability was stopped. Transesophageal heart echocardiography (Tee) was performed to observe the inadvertent internal air bubble and clamp the apical exhaust duct.

Patients from group B were maintained at complete pleural position during CPB, meanwhile, after the heartbeat standard tidal volume ventilation with pure oxygen, the airway pressure was kept at $10 \mathrm{~cm} \mathrm{H}_{2} \mathrm{O}$ of lung inflation. Cardiac cavity evacuation procedure and the evacuation time standard was the same as in group A. The hemodynamic parameters [mean arterial pressure (MAP), central venous pressure (CVP), pulmonary arterial pressure (PASP), pulmonary capillary wedge pressure (PCWP), systemic circulation resistance (SVR), cardiac output (CO), and cardiac index (CI)] of the two groups were recorded before anesthesia induction $\left(\mathrm{T}_{0}\right)$, immediately after the shutdown $\left(\mathrm{T}_{1}\right), 1 \mathrm{~h}$ after surgery $\left(\mathrm{T}_{2}\right), 3 \mathrm{~h}$ after surgery $\left(\mathrm{T}_{3}\right)$, $6 \mathrm{~h}$ after surgery $\left(\mathrm{T}_{4}\right)$ and $24 \mathrm{~h}$ after surgery $\left(\mathrm{T}_{5}\right)$. Patients were treated with $5 \mathrm{ml}$ venous blood placed into the EDTA anticoagulant tube at each time-point. After centrifugation for $2 \mathrm{~min}(2,500 \mathrm{x} \mathrm{g})$, the supernatant was extracted and cryopreserved at $-20^{\circ} \mathrm{C}$. After blood collection at each time-point, the concentrations of IL-6, IL-8, IL-10, TNF- $\alpha$ and TIMP-1 were determined by enzyme-linked immunosorbent assay.

Statistical analysis. The data are expressed by mean addition and subtraction standard deviation (mean \pm SD), and the data were processed by statistical product and service solutions (SPSS) 20 statistical software (IBM Corp., Armonk, NY, USA). The t-test was used between the two groups, and the Chi-square test was used to analyse the data. The three groups were compared by single factor analysis of variance. The difference of $\mathrm{p}<0.05$ was statistically significant.

\section{Results}

Table II showed that the MAP, PAP, CO, CI, T 5 , PCWP, CVP and SVR in the patients of group $\mathrm{A}$ and the group $\mathrm{B}$ were not statistically significant at the time of $\mathrm{T}_{0}$ and $\mathrm{T}_{5}(\mathrm{p}>0.05)$. The MAP, PAP, CO, CI, PCWP, CVP and SVR indexes in group B were statistically significant compared with those in group A at the time of $\mathrm{T}_{1}, \mathrm{~T}_{2}, \mathrm{~T}_{3}$, and $\mathrm{T}_{4}(\mathrm{p}<0.05)$. The hemodynamic parameters of patients in group A at each time-point fluctuated less than those in group B.

There was no statistical significance in IL-6, IL-8, IL-10, TNF- $\alpha$ and TIMP-1 between group A and group B patients at the $\mathrm{T}_{0}$ time $(\mathrm{p}>0.05)$. The levels of IL-6, IL-8, B, IL-10, TNF- $\alpha$ and TIMP-1 in group B patients at $T_{1}, T_{2}, T_{3}$ and $T_{4}$ moments were statistically significant compared with those in group A $(p<0.05)$. The indexes of IL-6, IL- 8 and TNF- $\alpha$ in group $B$ patients were statistically significant at the $T_{5}$ moment compared with those in group A $(\mathrm{p}<0.05)$. The IL-10 and TIMP-1 of two groups were not statistically significant at the $\mathrm{T}_{5}$ moment $(\mathrm{p}>0.05)$ (Table III).

The operating time, CPB time, aortic clamp time, intraoperative blood loss, postoperative tube time, ICU stay time, hospital stay time and pulmonary infection of patients in group A were significantly less than those in group B (Table IV).

\section{Discussion}

Many studies and clinical work show that cardiac valve replacement under CPB has a definite curative effect on patients with valvular heart disease, but there are many complications (residual bubbles remaining in the heart cavity and pulmonary vein system tend to enter the left ventricular system after cardiac arrest or after cardiopulmonary bypass, resulting in left ventricular dysfunction and hemodynamic abnormalities). Therefore, how to reduce or even eliminate the residual bubbles remaining in the heart cavity 
Table III. Comparison of inflammatory mediators at different time-points before and after operation in the two groups (n=30, mean $\pm \mathrm{SD})$.

\begin{tabular}{lccccccc}
\hline Indices & Groups & $\mathrm{T}_{0}$ & $\mathrm{~T}_{1}$ & $\mathrm{~T}_{2}$ & $\mathrm{~T}_{3}$ & $\mathrm{~T}_{4}$ & $\mathrm{~T}_{5}$ \\
\hline IL-6 & Group A & $4.17 \pm 1.68$ & $102.73 \pm 54.75$ & $151.74 \pm 78.73$ & $178.01 \pm 28.21$ & $136.84 \pm 61.91$ & $103.28 \pm 69.55$ \\
& Group B & $6.13 \pm 2.74$ & $141.89 \pm 29.34^{\mathrm{a}}$ & $223.65 \pm 47.72^{\mathrm{a}}$ & $211.18 \pm 93.63^{\mathrm{a}}$ & $172.36 \pm 25.13^{\mathrm{a}}$ & $82.56 \pm 17.58^{\mathrm{a}}$ \\
IL-8 & Group A & $17.71 \pm 5.47$ & $31.34 \pm 24.30$ & $38.13 \pm 19.79$ & $28.61 \pm 7.28$ & $21.75 \pm 8.51$ & $16.67 \pm 5.31$ \\
& Group B & $20.31 \pm 4.13$ & $46.23 \pm 8.23^{\mathrm{a}}$ & $57.23 \pm 8.42^{\mathrm{a}}$ & $35.89 \pm 9.52^{\mathrm{a}}$ & $30.75 \pm 15.41^{\mathrm{a}}$ & $26.34 \pm 18.34^{\mathrm{a}}$ \\
IL-10 & Group A & $13.93 \pm 0.38$ & $413.98 \pm 141.12$ & $435.85 \pm 42.38$ & $162.85 \pm 31.57$ & $79.68 \pm 5.93$ & $9.87 \pm 0.45$ \\
& Group B & $12.04 \pm 0.51$ & $520.49 \pm 194.23^{\mathrm{a}}$ & $579.33 \pm 53.41^{\mathrm{a}}$ & $210.35 \pm 11.92^{\mathrm{a}}$ & $129.28 \pm 4.73^{\mathrm{a}}$ & $10.55 \pm 2.71$ \\
TNF- $\alpha$ & Group A & $22.71 \pm 4.70$ & $25.45 \pm 3.52$ & $24.95 \pm 6.06$ & $28.34 \pm 8.31$ & $18.98 \pm 3.14$ & $20.42 \pm 5.29$ \\
& Group B & $18.43 \pm 3.81$ & $43.28 \pm 6.94^{\mathrm{a}}$ & $57.47 \pm 9.25^{\mathrm{a}}$ & $63.17 \pm 9.62^{\mathrm{a}}$ & $71.35 \pm 6.78^{\mathrm{a}}$ & $43.69 \pm 9.63^{\mathrm{a}}$ \\
TIMP-1 & Group A & $3,382.39 \pm 527.42$ & $2,188.24 \pm 124.31$ & $2,141.21 \pm 132.45$ & $1,573.15 \pm 123.01$ & $1,236.34 \pm 101.27$ & $1,356.55 \pm 126.37$ \\
& Group B & $3,249.63 \pm 367.27$ & $2,711.14 \pm 191.02^{\mathrm{a}}$ & $2,437.94 \pm 195.87^{\mathrm{a}}$ & $1,823.65 \pm 97.19^{\mathrm{a}}$ & $1,690.2 \pm 143.60^{\mathrm{a}}$ & $1,349.48 \pm 92.13$ \\
\hline
\end{tabular}

${ }^{\mathrm{a}}$ For group B, compared with group A, $\mathrm{p}<0.05$.

Table IV. Comparison of intraoperative and postoperative conditions between the two groups $(n=30$, mean \pm SD).

\begin{tabular}{lcc}
\hline Patient characteristics & Group A (n=30) & Group B (n=30) \\
\hline Operating time (min) & $213.71 \pm 23.78$ & $246.59 \pm 34.56^{\mathrm{a}}$ \\
CPB time (min) & $99.62 \pm 16.32$ & $118.73 \pm 21.13^{\mathrm{a}}$ \\
Aortic clamp time (min) & $77.56 \pm 7.41$ & $89.65 \pm 9.23^{\mathrm{a}}$ \\
Intraoperative blood & $550 \pm 50.71$ & $660 \pm 78.63^{\mathrm{a}}$ \\
loss (ml) & & \\
Postoperative tube & $6.71 \pm 0.65$ & $9.6 \pm 0.82^{\mathrm{a}}$ \\
time (h) & & \\
ICU stay time (h) & $39.50 \pm 5.63$ & $48.73 \pm 6.21^{\mathrm{a}}$ \\
Hospital stay time (days) & $14.30 \pm 3.46$ & $18.30 \pm 5.41^{\mathrm{a}}$ \\
Pulmonary infection (case) & 1 & $3^{\mathrm{a}}$ \\
\hline
\end{tabular}

${ }^{\mathrm{a}}$ For group B, compared with group A, $\mathrm{p}<0.05$.

and pulmonary vein system remains an important problem to be solved. The concept of Lund was proposed by Professor Eker of Lund University in Sweden $(13,14)$, which is mainly used to improve the prognosis of patients with severe traumatic brain injury. According to the Lund concept, we named our exhaust method Lund exhaust technology.

MAP, CVP, PASP, PCWP, SVR, CO and CI are the main indexes of the hemodynamic response. MAP is the average of arterial blood pressure during a cardiac cycle, and the average arterial pressure in normal adults is $70-105 \mathrm{mmHg}$. It was found that the increase of MAP from $65 \mathrm{mmHg}$ to normal level can improve microcirculation (15) in patients with hypertensive septic shock. The mean arterial pressure of radial artery reliably reflects the mean arterial pressure (16) in simple cardiac surgery in children.

CVP is the pressure of the upper and inferior vena cava into the right atrium, which is measured by the upper or inferior vena cava or the right atrium. It reflects the right atrial pressure, and is one of the main indexes of clinical hemodynamic observation. CVP was affected by 3 factors: cardiac function, circulating blood volume and vascular tension. The determination of CVP is important for understanding the effective circulating blood volume and cardiac function. The normal value is $0.05-0.12 \mathrm{kPa}$ (5-12 $\mathrm{cm} \mathrm{H}_{2} \mathrm{O}$ ) (17). In resting state, the normal systolic pressure of adult pulmonary artery was $18-25 \mathrm{mmHg}$, and the systolic pressure and mean pressure of pulmonary artery were more than 30 and $20 \mathrm{mmHg}$ in resting state, which was pulmonary hypertension (18). PCWP is the most common and important monitoring indicator in clinical hemodynamic monitoring. It can reflect the left ventricular filling pressure and can be used to determine the left ventricular function in patients with hemorrhagic shock. If PCWP is lowered, prompt blood volume should be indicated. Patients with cardiogenic shock, if PCWP is elevated, indicate left heart failure or pulmonary edema, and their normal value is $6-12 \mathrm{mmHg}$ (19). SVR refers to the blood flow resistance during circulation in the body. It originates from frictional resistance between blood flow and the walls of blood vessels as well as frictional resistance within the blood. It is related to blood viscosity, length of blood vessel, elasticity and radius of vessels. $\mathrm{CO}$ refers to the total volume of blood produced by a single ventricle per minute, which can be used to determine cardiac function, diagnose heart failure and low back syndrome, estimate prognosis, and guide treatment. CI refers to the body surface area (square meters) calculated cardiac output (known as the heart index) and can be of different sizes of patients for direct comparison.

The results of this study showed that there was no difference in MAP, CVP, PASP, PCWP, SVR, CO, and CI before and after anesthesia induction in group B compared with group A. The indexes of MAP, PAP, CO, CI, PCWP, CVP and SVR in group B were statistically significant when the patients were stopped immediately, $1 \mathrm{~h}$ after operation, $3 \mathrm{~h}$ after operation and $6 \mathrm{~h}$ after operation compared with group A. Especially SVR in group B was significantly higher than that of group A. The hemodynamic indexes of patients in group B fluctuated significantly at each time-point compared with those 
in group $\mathrm{A}$, indicating that the Lund exhaust technique can reduce the fluctuation of hemodynamics and maintain the stability of heart and lung function in patients. However, at $24 \mathrm{~h}$ after operation, there was no difference in hemodynamic parameters between the two groups, indicating that the residual bubble remaining in the heart cavity and pulmonary vein system basically restored the hemodynamic effects.

IL-6, IL-8, and IL-10 are early markers of tissue damage sensitive material. The concentration, size, operation time and severity of infection and postoperative complications, were directly related to the extent of the damage and increased after operation (20-22). IL-6 can induce B cell differentiation, produce antibodies, and induce $\mathrm{T}$ cell activation, proliferation and differentiation, as well as participate in the immune response of the organism, and function as a promoter of inflammatory reaction. IL-8 can stimulate neutrophils, T lymphocytes and eosinophils chemotaxis, promote neutrophil degranulation, release elastase, endothelial injury, microcirculation of blood stasis, tissue necrosis, organ function injury caused by IL-10 and is a negative regulatory factor, mainly produced by Th 2 cells, activated B cells, monocytes, macrophages involved in immune cells, inflammatory cells, tumor cells and other cell biological regulation, playing an important role in autoimmune diseases, serious infectious diseases, cancer and transplantation immunity in a variety of diseases (23). TNF- $\alpha$ is an inflammatory mediator of the earliest and most important process of inflammation. It can activate neutrophils and lymphocytes to endothelial cell permeability increase, regulating synthesis of other tissue metabolic activity and prompt other cytokines (24). TIMP-1, a tissue inhibitor of metalloproteinases, is a glycoprotein that is expressed in a variety of organisms. TIMP-1 is an inhibitory molecule that regulates matrix metalloproteinases (MMPs), and disintegrinmetalloproteinases (ADAMs and ADAMTSs). In regulating MMPs, TIMP1 plays a crucial role in extracellular matrix (ECM) composition, wound healing and pregnancy (25).

Clinical studies have shown that surgical trauma, anesthesia, and stress can produce strong peripheral inflammatory reaction, promote inflammatory cytokines, such as TNF- $\alpha$, IL-1, IL-6, IL-8, IL-10 and other large, inflammatory reaction and activation of microglia induced by excessive expansion of the central system (26). In this experiment, Lund exhaust technology we used in surgical CPB undergoing cardiac valve replacement, by detecting the concentration of plasma IL-6, IL-8, IL-10, TNF- $\alpha$ and TIMP-1 to reveal whether Lund exhaust technology reduces the expression of inflammatory cytokines. Table III data showed that the IL-6, IL-8, IL-10, TNF- $\alpha$ and TIMP-1 in the two groups were not statistically significant before the induction of anesthesia. The levels of IL-6, IL-8, IL-10, TNF- $\alpha$, and TIMP-1 in group B were significantly higher than those in group $\mathrm{A}$ at downtime, $1 \mathrm{~h}$ after operation, $3 \mathrm{~h}$ after operation and $6 \mathrm{~h}$ after operation. In group B, the fluctuation of inflammatory factors at each time-point was larger than that in group A. Twenty-four hours after surgery, the two groups of patients with IL-10, TIMP-1 indicators were not statistically significant. Compared with anesthesia before induction, there was no statistical significance, indicating that IL-10, and TIMP-1 were restored at $24 \mathrm{~h}$ after surgery. Twenty-four hours after surgery, the two groups of patients with IL-6, IL-8, TNF- $\alpha$ indicators were statistically significant, and compared with pre-anesthesia induction, they were also statistically significant. The IL-6, IL-8 and TNF- $\alpha$ in group A were closer to the preoperative group than those in group B, indicating that IL-6, IL-8 and TNF- $\alpha$ did not recover at 24 postoperative fashion, but the Lund exhaust technique could promote the recovery of inflammatory factors. Table IV data show that Lund exhaust technology can significantly improve patients' lung function, and help patients with intraoperative stability and postoperative rehabilitation.

In conclusion, Lund exhaust technology can significantly reduce the hemodynamic changes of patients, decrease secretion of inflammatory factors during and after operation, as well as improve lung function, factors that are worthy of clinical promotion.

\section{Acknowledgements}

Not applicable.

\section{Funding}

This study was supported by Health and Family Planning Commission of Zhe Jiang Province (no 201350098).

\section{Availability of data and materials}

All data generated or analyzed during this study are in this published article.

\section{Authors' contributions}

JZ and WZ were responsible for the conception and design of the study. GS and XY collected the patient data. JG and TZ analyzed the patient data. All authors have read and approved the manuscript.

\section{Ethics approval and consent to participate}

The study was carried out in Sir Run Run Shaw Hospital of Zhejiang University (Hangzhou, China). Informed consent was signed by all the participants or their families.

\section{Patient consent for publication}

Not applicable.

\section{Competing interests}

The authors declare that they have no competing interests.

\section{References}

1. Li D, Liu W, Ma D, Yun F, Li S and Liu F: An effective treatment for heart failure caused by valvular heart diseases: Thoracic sympathetic block. J Invest Surg: 1-5, 2017. Feb 27, 2017 (Epub ahead of print). doi: 10.1080/08941939.2017.1284965.

2. Laudari S and Subramanyam G: A study of spectrum of rheumatic heart disease in a tertiary care hospital in Central Nepal. Int J Cardiol Heart Vasc 15: 26-30, 2017.

3. Fallahiarezoudar E, Ahmadipourroudposht M, Idris A and Mohd Yusof N: A review of: Application of synthetic scaffold in tissue engineering heart valves. Mater Sci Eng C 48: 556-565, 2015. 
4. Liu F, Xu D, Zhang K and Zhang J: Effects of tranexamic acid on coagulation indexes of patients undergoing heart valve replacement surgery under cardiopulmonary bypass. Int J Immunopathol Pharmacol 29: 753-758, 2016.

5. Vedel AG, Holmgaard F, Rasmussen LS, Paulson OB, Thomsen C, Danielsen ER, Langkilde A, Goetze JP, Lange T, Ravn HB, et al Perfusion Pressure Cerebral Infarct (PPCI) trial - the importance of mean arterial pressure during cardiopulmonary bypass to prevent cerebral complications after cardiac surgery: Study protocol for a randomised controlled trial. Trials 17: 247, 2016.

6. Schmitt KR, Fedarava K, Justus G, Redlin M, Böttcher W, Delmo Walter EM, Hetzer R, Berger F and Miera O: Hypothermia during cardiopulmonary bypass increases need for inotropic support but does not impact inflammation in children undergoing surgical ventricular septal defect closure. Artif Organs 40 470-479, 2016

7. Dora KA, Stanley CP, Al Jaaly E, Fiorentino F, Ascione R, Reeves BC and Angelini GD: Isolated human pulmonary artery structure and function pre- and post-cardiopulmonary bypass surgery. J Am Heart Assoc 5: 5, 2016.

8. Ghista DN and Kabinejadian F: Coronary artery bypass grafting hemodynamics and anastomosis design: A biomedical engineering review. Biomed Eng Online 12: 129, 2013.

9. Yang XL, Wang D, Zhang GY and Guo XL: Comparison of the myocardial protective effect of sevoflurane versus propofol in patients undergoing heart valve replacement surgery with cardiopulmonary bypass. BMC Anesthesiol 17: 37, 2017.

10. Budak AB, McCusker K and Gunaydin S: A structured blood conservation program in pediatric cardiac surgery. Eur Rev Med Pharmacol Sci 21: 1074-1079, 2017.

11. Alassar A, Soppa G, Edsell M, Rich P, Roy D, Chis Ster I, Joyce R, Valencia O, Barrick T, Howe F, et al: Incidence and mechanisms of cerebral ischemia after transcatheter aortic valve implantation compared with surgical aortic valve replacement. Ann Thorac Surg 99: 802-808, 2015.

12. Jiang L, Hu M, Lu Y, Cao Y, Chang Y and Dai Z: The protective effects of dexmedetomidine on ischemic brain injury: A metaanalysis. J Clin Anesth 40: 25-32, 2017.

13. Andrews PJ and Citerio G: Lund Therapy - pathophysiologybased therapy or contrived over-interpretation of limited data? Intensive Care Med 32: 1461-1463, 2006.

14. Grände PO: Critical evaluation of the Lund concept for treatment of severe traumatic head injury, 25 years after its introduction. Front Neurol 8: 315, 2017.

15. Xu JY, Ma SQ, Pan C, He HL, Cai SX, Hu SL, Liu AR, Liu L, Huang YZ, Guo FM, et al: A high mean arterial pressure target is associated with improved microcirculation in septic shock patients with previous hypertension: A prospective open label study. Crit Care 19: 130, 2015.

16. Cetin S, Pirat A, Kundakci A, Camkiran A, Zeyneloglu P, Ozkan M and Arslan G: Radial mean arterial pressure reliably reflects femoral mean arterial pressure in uncomplicated pediatric cardiac surgery. J Cardiothorac Vasc Anesth 28: 76-83, 2014.
17. Hossein-Nejad H, Mohammadinejad P and Ahmadi F: Internal jugular vein/common carotid artery cross-sectional area ratio and central venous pressure. J Clin Ultrasound 44: 312-318, 2016.

18. Molkentin JP, Nägele MP, Frank M, Sudano I, Enseleit F, Wilhelm MJ, Lüscher TF, Maisano F, Ruschitzka F and Flammer AJ: Prognostic value of mean pulmonary artery pressure in the stable phase after heart transplantation. Eur J Cardiothorac Surg 52: 775-780, 2017.

19. Grinstein J, Rodgers D, Kalantari S, Sayer G, Kim GH, Sarswat N, Adatya S, Ota T, Jeevanandam V, Burkhoff D, et al: HVAD Waveform analysis as a noninvasive marker of pulmonary capillary wedge pressure: A first step toward the development of a smart left ventricular assist device pump. ASAIO J 64: 10-15, 2018.

20. LeBlanc NL, Scollan KF and Stieger-Vanegas SM: Cardiac output measured by use of electrocardiogram-gated 64-slice multidector computed tomography, echocardiography, and thermodilution in healthy dogs. Am J Vet Res 78: 818-827, 2017.

21. Kubota K, Takeno S, Taruya T, Sasaki A, Ishino T and Hirakawa K: IL-5 and IL-6 are increased in the frontal recess of eosinophilic chronic rhinosinusitis patients. J Otolaryngol Head Neck Surg 46: 36, 2017.

22. Roeleveld DM, Marijnissen RJ, Walgreen B, Helsen MM, van den Bersselaar L, van de Loo FA, van Lent PL, van der Kraan PM, van den Berg WB and Koenders MI: Higher efficacy of anti-IL-6/IL-21 combination therapy compared to monotherapy in the induction phase of Th17-driven experimental arthritis. PLoS One 12: e0171757, 2017.

23. Zhu L, Shi T, Zhong C, Wang Y, Chang M and Liu X: IL-10 and IL-10 receptor mutations in very early onset inflammatory bowel disease. Gastroenterol Res 10: 65-69, 2017.

24. Behrendt P, Häfelein K, Preusse-Prange A, Bayer A, Seekamp A and Kurz B: IL-10 ameliorates TNF- $\alpha$ induced meniscus degeneration in mature meniscal tissue in vitro. BMC Musculoskelet Disord 18: 197, 2017.

25. Vilmi-Kerälä T, Lauhio A, Tervahartiala T, Palomäki O, Uotila J, Sorsa T and Palomäki A: Subclinical inflammation associated with prolonged TIMP-1 upregulation and arterial stiffness after gestational diabetes mellitus: A hospital-based cohort study. Cardiovasc Diabetol 16: 49, 2017.

26. Wakabayashi S, Yamaguchi K, Kumakura S, Murakami T, Someya A, Kajiyama Y, Nagaoka I and Inada E: Effects of anesthesia with sevoflurane and propofol on the cytokine/chemokine production at the airway epithelium during esophagectomy. Int J Mol Med 34: 137-144, 2014.

This work is licensed under a Creative Commons Attribution-NonCommercial-NoDerivatives 4.0 International (CC BY-NC-ND 4.0) License. 